\title{
El hábitat popular en Francia: elementos de reflexión con miradas hacia el Perú
}

L'habitat populaire en France: éléments de réflexion avec le Pérou en perspective Popular habitat in France: some reflections with Peru in mind

Jean-Claude Driant, Jérémy Robert y Catherine Paquette

\section{CpenEdition}

Edición electrónica

URL: http://journals.openedition.org/bifea/8580

DOI: $10.4000 /$ bifea. 8580

ISSN: 2076-5827

Editor

Institut Français d'Études Andines

Edición impresa

Fecha de publicación: 8 diciembre 2017

Paginación: 413-429

ISSN: 0303-7495

Referencia electrónica

Jean-Claude Driant, Jérémy Robert y Catherine Paquette, «El hábitat popular en Francia: elementos de reflexión con miradas hacia el Perú », Bulletin de l'Institut français d'études andines [En línea], 46 (3)| 2017, Publicado el 08 diciembre 2017, consultado el 05 noviembre 2020. URL : http:// journals.openedition.org/bifea/8580 ; DOI : https://doi.org/10.4000/bifea.8580

\section{(c) (†) $९$}

Les contenus du Bulletin de l'Institut français d'études andines sont mis à disposition selon les termes de la licence Creative Commons Attribution - Pas d'Utilisation Commerciale - Pas de Modification 4.0 International. 


\title{
El hábitat popular en Francia: elementos de reflexión con miradas hacia el Perú*
}

\author{
Jean-Claude Driant** \\ Entrevista realizada por Jérémy Robert $^{* * *}$ y \\ Catherine Paquette ${ }^{* * *}$
}

\begin{abstract}
Resumen
El lugar del hábitat popular en la ciudad sostenible es el eje central de la entrevista que se le realizó a Jean-Claude Driant, quien estudió el caso de Lima hace treinta años y es actualmente especialista del tema de la vivienda en Francia. Esta conversación, generada con motivo del Foro Urbano Nacional «¿Ciudades populares, ciudades sostenibles? El hábitat popular en debate» organizado en septiembre de 2016 en Lima, propone abordar diferentes aspectos de los barrios populares, y en particular de las políticas públicas de las que son objeto. Se partió de la hipótesis que la confrontación de realidades distintas permite hacer emerger ideas originales o, por lo menos, renovar las formas de ver y de formular el problema. La «mixidad» social, la participación o la sostenibilidad son algunos de los temas abordados, desde la experiencia francesa, con la realidad peruana en la mira.
\end{abstract}

Palabras clave: barrios populares, vivienda social, «mixidad» social, participación, ciudad sostenible, Francia, Perú

* Traducción de la entrevista: Kattia Pacheco, Anne-Marie Brougère y Vanessa Ponce de León.

** Profesor de la Escuela de Urbanismo de París (École d'Urbanisme de Paris-EUP, Université Paris-Est), investigador del Lab'Urba. E-mail: driant@u-pec.fr

*** Investigador principal en el Instituto Francés de Estudios Andinos - IFEA (UMIFRE 17 MEAE / CNRS USR 3337 América Latina). E-mail: jeremy.robert@cnrs.fr

${ }^{* * * *}$ Encargada de investigación en el Institut de Recherche pour le Développement (IRD), Laboratoire Population Environnement Développement (LPED), Aix-Marseille Université/IRD. E-mail: catherine. paquette@ird.fr 


\title{
L'habitat populaire en France: éléments de réflexion avec le Pérou en perspective
}

\author{
Résumé \\ La place de l'habitat populaire dans la ville durable est la question centrale discutée dans cette interview \\ de Jean-Claude Driant, qui a étudié le cas de Lima il y a trente ans et est actuellement spécialiste du \\ logement en France. Cette discussion, générée à l'occasion du Forum urbain national «íCiudades \\ populares, ciudades sostenibles? El hábitat popular en debate», organisé en septembre 2016 à Lima, \\ propose d'aborder différents aspects des quartiers populaires, et en particulier les politiques publiques \\ dont ils font l'objet. Elle part de l'hypothèse que la confrontation de réalités différentes permet de \\ faire émerger des idées originales, ou pour le moins, de rénover la façon de voir et de formuler le \\ problème. La mixité sociale, la participation ou la durabilité son quelques-uns des thèmes abordés, \\ depuis l'expérience française, avec la réalité péruvienne en ligne de mire.
}

Mots-clés : habitat populaire, logements sociaux, mixité sociale, participation, ville durable, France, Pérou

\section{Popular habitat in France: some reflections with Peru in mind}

\begin{abstract}
The place of the popular habitat within the sustainable city is the central question discussed in this interview of Jean-Claude Driant, a specialist in the housing questions in France, who worked on the case of Lima 30 years ago. This discussion, begun on the occasion of the national urban fórum entitled "Ciudades populares, ciudades sostenibles? El habitat popular en debate" in September, 2016 in Lima, suggests an approach to different aspects of popular neighborhoods, and its associated public policies. It assumes that the confrontation of different realities will yield original ideas, or at least, renew the ways of addressing and formulating the problem. "Social mixity", participation andsustainability are some of the issues tackled, from the French standpoint, while putting the Peruvian reality in perspective.
\end{abstract}

Key words: popular habitat, social housing, "social mixity", participation, sustainable city, France, Peru

En el marco del Foro Urbano «iCiudades populares, ciudades sostenibles? El hábitat popular en debate» organizado en septiembre de 2016 en Lima, el IFEA invitó a Jean-Claude Driant a confrontar su experiencia del hábitat popular en Francia con la realidad peruana que estudió hace treinta años. Geógrafo y doctor en Urbanismo por la Université Paris-Est Créteil, Jean-Claude Driant realizó su investigación doctoral sobre las barriadas limeñas a fines de la década de 1980 con el apoyo del Instituto Francés de Estudios Andinos (IFEA), del Centro de Investigación, Documentación y Asesoría Poblacional (CIDAP) y del Centro de Estudios y Promoción del Desarrollo (DESCO). Como resultado de esta investigación, publicó el libro Las Barriadas de Lima. Historia e interpretación (1991) que se convirtió en una de las principales referencias sobre la vivienda popular en las ciudades de Latinoamérica. Continuó su trayectoria profesional en Francia como profesor de la Escuela de Urbanismo de París (École d'Urbanisme de Paris), de la cual fue director durante el período 2001-2006. Dirigió, a su vez, el laboratorio de investigación Lab'Urba de 2005 a 2014. En la actualidad, Jean- 
Claude Driant enfoca sus investigaciones en las políticas nacionales y locales del hábitat, la vivienda social y los mercados inmobiliarios en Francia y en Europa.

El objetivo de la entrevista que se le realizó fue generar una discusión original sobre los barrios populares, más allá de los enfoques tradicionales, teniendo como hipótesis inicial que la confrontación de realidades distintas permite renovar las formas de mirar y formular las problemáticas. La temática del hábitat popular se plantea en términos muy diferentes en Francia y en América Latina, por la existencia de contextos socioeconómicos, urbanos y políticos distintos. Sin embargo, existen preocupaciones comunes en las ciudades peruanas y francesas, como las desigualdades socioespaciales y la segregación urbana, y también el rol del Estado y de las políticas públicas de vivienda. En este contexto, se le planteó a Jean-Claude Driant una serie de preguntas1.

\section{Después de su trabajo en las barriadas de Lima en los años 1980, ¿cuál ha sido su trayectoria? Y regresando a Lima después de varios años, icuál ha sido su percepción de la ciudad?}

Trabajé en Lima con Gustavo Riofrío, entre 1984 y 1988, inicialmente en el marco de un acuerdo de cooperación entre el IFEA y la ONG CIDAP, y luego para realizar una investigación más personal en el marco del doctorado que sustenté en mayo de 1989, acerca de la consolidación y la reproducción de las barriadas de Lima. La primera de estas investigaciones fue publicada en Lima en 1987 (Riofrío \& Driant, 1987) y el primer volumen de mi tesis lo fue en 1991 (Driant, 1991).

Esta experiencia peruana fue absolutamente fundamental para mí puesto que fue en esta ocasión que desarrollé mi gusto por la investigación y la enseñanza (dicté algunos cursos en diferentes universidades en Lima en 1985 y en 1987) y mi interés por la problemática de la vivienda y del hábitat popular. Sin duda yo no habría realizado un doctorado y mucho menos ingresado a la enseñanza superior si no hubiese realizado estos estudios en Lima. Estoy particularmente agradecido con Jean-Paul Deler, director del IFEA en la época de mi primera estadía como voluntario del servicio nacional. Sin embargo, la vida me ha llevado rápidamente hacia otros horizontes. Luego de mi tesis, trabajé inicialmente en una empresa de consultoría en urbanismo en París; posteriormente estuve involucrado, bajo las direcciones sucesivas de François Ascher y Henri Coing, en programas de investigación y actividades de animación del medio científico centrados en el contexto francés del hábitat.

Es así como progresivamente he logrado una competencia científica y una experticia en temas del mercado de la vivienda y de las políticas del hábitat en Francia. Esta competencia me ha permitido integrar la enseñanza superior en 1994 y participar, desde entonces, en la formación de jóvenes profesionales especialistas en temas del hábitat. Asimismo, me permite asesorar a doctorandos quienes mayoritariamente estudian las problemáticas francesas. Desde esta fecha

1 Para dar elementos de referencia y de comparación, algunos cuadros fueron agregados a la entrevista. 
soy profesor-investigador de la actual École d'Urbanisme de Paris², donde asumí diferentes cargos administrativos.

A pesar de que mis actividades parecen haberme distanciado de la experiencia latinoamericana, esta ha marcado profundamente mi trayectoria. Orientó mis prioridades hacia el tema del hábitat popular, a la intersección de los mecanismos de mercado y de las políticas públicas, en una lógica finalmente bastante cercana a aquella que me llevó a analizar las barriadas de Lima. Aun durante el tiempo que estuve lejos de Lima, entre febrero de 1988 y septiembre de 2016, pude mantener la relación con mis colegas y amigos peruanos. Además, mi interés por la región se mantuvo gracias a los intercambios regulares con numerosos estudiantes latinoamericanos que recibimos en la universidad en París.

Es en este contexto que recibí la invitación del IFEA para participar en el foro urbano de septiembre de 2016. Regresar a Lima luego de más de 28 años me generó una emoción muy grande. Dejé la ciudad en medio de una ola de terrorismo y de restricciones de la libre circulación (toque de queda), con una inflación desemesurada y bajo la primera presidencia de Alan García. Ahora la encuentro convertida en la capital mundial de la gastronomía, sin comercio ambulatorio en las calles del casco histórico y saturada de malls rutilantes en los alrededores de las barriadas que yo había estudiado 30 años atrás.

La ciudad ha cambiado profundamente. Los hermosos vecindarios de Miraflores y San Isidro se han globalizado y encontramos los mismos anuncios publicitarios que en otras partes del mundo; Barranco ha conservado su encanto bohemio y presenta todos los signos exteriores de una «gentrificación» ya antigua. El metro aéreo, cuya espectacular construcción provocaba ironía en 1988, une hoy en día Villa el Salvador y San Juan de Lurigancho. Los barrios de las clases medias en el centro de la aglomeración se han densificado considerablemente: en muchas partes los condominios han remplazado las pequeñas casas. El tránsito vehicular, que ya era complicado, se ha vuelto aún más infernal; los «escarabajos» antes omnipresentes han desaparecido; Uber compite con los taxis pero el tiempo parece suspendido sobre las combis y los microbuses que han conservado su incomodidad y la aterradora destreza de manejo de sus choferes.

En cuanto a las barriadas, ellas siguen presentes y continúan creciendo. Las conclusiones de nuestras publicaciones de los años 1980 parecen permanecer vigentes: consolidación de los sectores más antiguos en donde es difícil encontrar rastros de invasores y de construcción precaria a base de esteras, pero existe también un crecimiento constante de nuevos barrios. Basta subir a las alturas del distrito del Rímac o de San Juan de Miraflores para encontrar formas de producción urbana cada vez más precarias y extendidas en las laderas de los cerros.

Una estancia de solo cinco días no permite captar a profundidad todas las evoluciones de una ciudad, pero la impresión que he tenido combina la intensa

2 La École d'Urbanisme de Paris fue creada en 2015, resultado de la fusión del Institut d'Urbanisme de Paris (IUP, Université Paris Est Créteil) y del Institut Français d'Urbanisme (IFU, Université Paris Est Marne-la-Vallée). 
transformación que ha hecho posible la salida de la aguda crisis de los años 1980 y el crecimiento económico de las últimas décadas, con numerosas permanencias. La pobreza aún marca profundamente esta ciudad.

\section{¿Cuáles son los grandes debates en Francia y cómo se relacionan con los temas de discusión en América Latina?}

Respecto al hábitat popular, los debates franceses son numerosos porque nos remiten a toda la gama de preguntas sobre la evolución de la sociedad urbana y su vínculo con el problema de la vivienda.

El primer debate es aquel, muy común, relacionado con el rol otorgado a la acción pública para tratar una cuestión que para la mayoría de los franceses es un asunto estrictamente privado. ¿El Estado debería intervenir en el mercado inmobiliario, aportando una oferta reglamentada de vivienda social? Es un debate que sobrepasa el marco estrictamente francés ya que evoca también al espíritu general de la Unión Europea, cuyas políticas económicas están fundadas en el respeto de las reglas de libre competencia y cuestiona toda intervención pública susceptible de perturbar el libre ejercicio de los mecanismos del mercado. Hay una sola excepción: cuando estas intervenciones públicas promueven servicios de interés económico general. ¿Hasta qué punto podemos calificar de esta manera la vivienda de alquiler social tal y como existe en Francia?

El modelo francés de vivienda social es el objeto del segundo debate, a la vez europeo e interno en el sistema francés (siendo un tema discrepante entre los programas de los candidatos de derecha y de izquierda en la elección presidencial de 2017). En efecto, además del hecho de que, caso único en Europa, las políticas nacionales y locales persiguen con gran continuidad el desarrollo de la oferta de vivienda social, el modelo francés sigue siendo muy «generalista». Por ello se diferencia del otro modelo, dominante en Europa, a menudo conocido como «residualista», en el cual la vivienda social está reservada para los más pobres y los más excluidos. En Francia, no solo los criterios de identificación de los beneficiarios potenciales son amplios3, sino que además el principio del «derecho a mantenerse en el lugar» impide, en la mayoría de los casos, desalojar a un inquilino cuyos ingresos aumentan. Mientras la izquierda histórica promueve un modelo generalista, universal (vivienda social para todos), la derecha promueve más bien la concentración del esfuerzo en los más pobres, dejando que los otros se acomoden a los mecanismos de mercado y a la promoción del acceso a la propiedad.

Esta problemática del lugar de la propiedad de la vivienda en el mercado y en las políticas constituye un tercer tema de debate, que también es factor de discrepancias políticas. La promoción del acceso a la propiedad a través de políticas de vivienda es una constante en Francia desde hace muchas décadas.

3 Cerca de las tres cuartas partes de los hogares franceses son elegibles para una forma de vivienda en alquiler social. 
Cuadro 1 - Peso del hábitat social en los contextos nacionales ${ }^{4}$

Estatus de ocupación de las residencias principales en Francia y en Perú en 2013

\begin{tabular}{|c|c|c|c|c|}
\hline \multirow{2}{*}{ Vivienda } & \multicolumn{2}{|c|}{ Francia } & \multicolumn{2}{c|}{ Perú } \\
\cline { 2 - 5 } & Vivienda propia & $57,9 \%$ & Vivienda propia & $65,3 \% 5$ \\
\hline $\begin{array}{c}\text { Vivienda } \\
\text { social }\end{array}$ & Alquiler & $19,9 \%$ & Alquiler & $12,9 \%$ \\
\hline \multirow{2}{*}{ Otros } & Otros estatus & $17,3 \%$ & $\begin{array}{c}\text { Vivienda social } \\
\text { propia }\end{array}$ & $4,4 \%$ \\
& & $4,8 \%$ & $\begin{array}{c}\text { Cedido por un } \\
\text { tercero }\end{array}$ & $12,8 \%$ \\
\cline { 3 - 5 } & & Otros estatus & $4,6 \%$ \\
\hline
\end{tabular}

Fuentes: Francia: INSEE (2013); Perú: INEI (2015)

Viviendas adquiridas o construidas con la ayuda de programas de vivienda social en el Perú por año ${ }^{6}$

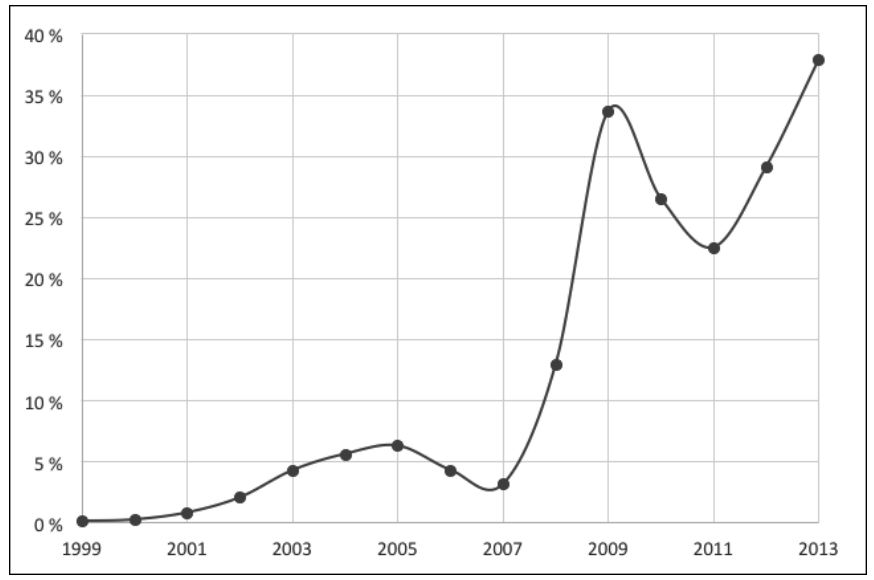

Fuente: Página web del Fondo MiVivienda (https://www.mivivienda.com.pe/PORTALWEB/ inversionistas/pagina.aspx?idpage $=139$ )

4 Los cuadros han sido realizados por Jean-Claude Driant para la situación francesa, y por Candice Pigeard y Jérémy Robert, para la situación peruana.

5 En el Perú, la elevada tasa de propietarios está asociada a una fuerte dinámica de autoconstrucción en los sectores populares. La Asociación de Desarrolladores Inmobiliarios (ADI Perú) estima que más del $60 \%$ de las nuevas viviendas construidas en Lima son edificadas bajo esta modalidad.

6 El apoyo a la vivienda social en el Perú es reciente y se encuentra en aumento desde 2006. En 2013, fueron 200000 hogares aproximadamente a nivel nacional que se beneficiaron de la ayuda (ya sea a través de un crédito para comprar o de un bono de construcción o ampliación). En Francia, esta política es mucho más antigua y se caracteriza por una tasa de crecimiento estable y por pocas construcciones nuevas. En 2014, 82418 nuevas viviendas sociales fueron construidas en Francia, lo que representa el 1,9\% con relación al stock total de viviendas, según el «Répertoire du Parc Locatif Social», 1 de enero de 2015 (Commisariat général au développement durable, 2015). 


\section{Cuadro 2 - Las competencias en materia de vivienda social}

\section{En Francia}

La estructura político-administrativa del territorio metropolitano de Francia (excluyendo sus territorios de ultramar) comprende tres niveles: las regiones, que son 13 desde 2015 (antes eran 22), los 96 departamentos y un poco menos de 36000 comunas. En cuanto al hábitat, desde la primera fase de descentralización en 1982, las comunas tienen la responsabilidad del reglamento urbanístico (plan local de urbanismo y entrega de permisos de construcción), los departamentos tienen competencia sobre los principales dominios de acción social (ingresos solidarios, políticas de la vejez, protección infantil, y también ayuda a los hogares con dificultades en materia de vivienda) y las regiones sobre el ordenamiento del territorio. Las líneas generales de las políticas de vivienda (ayuda financiera, regulación de la vivienda social...) continúan en manos del gobierno central. Desde el inicio de los años 2000 se ha iniciado un fuerte movimiento de constitución de intercomunidades (establecimientos públicos de cooperación intercomunal) que ahora abarca todo el territorio nacional, con cuatro niveles de integración (desde las más integradas, 15 metrópolis, hasta las intercomunidades rurales: los «reagrupamientos» de comunas). En total son 1266 comunidades en 2017. Es a este nivel que se ejerce la competencia de elaboración de programas locales del hábitat (PLH) que enuncian la política de producción y de gestión de la vivienda a escala intercomunal. Estas intercomunidades pueden firmar acuerdos de delegación con el Estado, los cuales les permiten tomar su lugar para entregar, en su territorio, subsidios para la producción de viviendas sociales. El área metropolitana de París ha tardado mucho en lanzarse hacia las dinámicas intercomunales. En 2015, se creó la Metrópolis del Gran París (Métropole du Grand Paris) que «reagrupa» las 130 comunas del centro de la región île-de-France (incluida la ciudad de París). Esa Metrópolis está encargada de elaborar un plan metropolitano del hábitat (equivalente a un PLH) y podrá firmar un acuerdo de delegación con el Estado para la producción de viviendas sociales. Estos trámites están en proceso de elaboración. El Plan metropolitano del hábitat y el alojamiento del Gran París (Plan Métropolitain de l'Habitat et de l'Hébergement du Grand Paris) será aprobado en 2018.

Una ley de 2014 introdujo un mecanismo de control del precio del alquiler de las viviendas del sector privado. Inicialmente previsto para todas las grandes ciudades del país, finalmente fue implementado únicamente en París y en Lille. Se basa en la creación de un observatorio de viviendas que recoge una información estadística detallada sobre los alquileres en el sector privado. Esto permite hacer el cálculo del alquiler promedio por $\mathrm{m}^{2}$ para un conjunto de zonas homogéneas y en función del tamaño (en número de ambientes) y de la antigüedad de las viviendas. El Estado fija, sobre esta base, alquileres de referencia. Todos los alquileres de nuevos contratos deben situarse en un rango de menos 30\% y de más $20 \%$ del alquiler de referencia. Esta medida 
funciona en París desde 2016 y provocó fuertes protestas por parte de los profesionales del sector inmobiliario y de las asociaciones de propietarios, los cuales profetizaron que generaría una disminución de la oferta.

No existe, en cambio, ninguna regulación pública sobre el precio de venta de las viviendas en Francia (ni en ninguna parte de Europa).

\section{En el Perú}

La estructura político-administrativa del Perú comprende tres niveles administrativos: 25 regiones, 194 municipalidades provinciales y 1826 municipalidades distritales. La Municipalidad Metropolitana de Lima constituye un caso particular en la medida en que combina las funciones de un gobierno regional y provincial. Los gobiernos regionales y locales (provinciales y distritales) cumplen una función de planificación del ordenamiento del territorio en su ámbito respectivo. Las municipalidades provinciales están a cargo de la reglamentación urbanística y de la planificación integral del desarrollo urbano mientras que las municipalidades distritales tienen la responsabilidad de otorgar los permisos de construcción. Ambas (municipalidades provinciales y distritales) están encargadas de promover la ejecución de programas de ayuda social para las familias de escasos recursos.

En lo que respecta a la vivienda social, el gobierno central maneja las políticas de subvenciones y la promoción del acceso al crédito. El Estado opera principalmente a través del Fondo MIVIVIENDA S.A., creado en 1998 (Ley N. ${ }^{\circ}$ 26912) y denominado sociedad anónima desde 2006 (Ley de Conversión

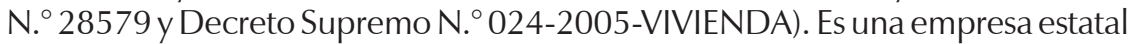
de derecho privado que pertenece al Ministerio de Vivienda, Construcción y Saneamiento. El Programa Techo Propio, creado en 2002 (Resolución Ministerial N. ${ }^{\circ}$ 054-2002-VIVIENDA), funciona desde agosto de 2003.

La política de vivienda social se basa en la colaboración estrecha entre el Estado, el sector inmobiliario y el sector financiero. El objetivo principal es facilitar la adquisición, la construcción y el mejoramiento de la vivienda. El Estado no produce ni vende viviendas sociales, rol que recae en los promotores privados que conciben, financian, ejecutan y comercializan proyectos de vivienda. Por su parte, el Estado estimula la demanda y facilita el acceso a las financieras intermediarias (Instituciones Financieras Intermediarias-IFI) o da una subvención directa a los hogares de bajos ingresos (Bono Familiar Habitacional-BFH)7. De esta manera, hay que diferenciar la «vivienda social»8, dirigida a la clase media y media alta, de la «vivienda de interés

7 El Bono Familiar Habitacional fue creado en 2002 por la Ley N. ${ }^{\circ} 27829$ y se hizo efectivo en agosto de 2003.

8 Solo es posible adquirir la vivienda social a través de créditos hipotecarios MIVIVIENDA y su valor varía entre 14 UIT (equivalente a S/. 51800 [US\$ 15800 aprox.]) y 70 UIT (S/. 259000 [US\$ 78964 aprox.]) [UIT=Unidad Impositiva Tributaria]. 
Social $\gg^{9}$, que está reservada para las familias menos favorecidas. Desde 2009, a través de los créditos hipotecarios del Fondo MIVIVIENDA S.A., el Estado ofrece el Bono del Buen Pagador que es una ayuda económica cuyo objetivo es promover el acceso al crédito.

La Ley Orgánica de Municipalidades prevé también programas municipales de vivienda de interés social. Este mecanismo de descentralización de la política de vivienda social se apoya en un acuerdo de cooperación interinstitucional entre una municipalidad provincial o distrital y el Fondo MIVIVIENDA S.A. Sin embargo, pocos programas han sido implementados, y los pocos intentos (Ilo, Arequipa) no tuvieron mayor éxito. Finalmente, desde 2015, el Estado se ha comprometido con una política de promoción del alquiler, con la implementación de un nuevo marco legislativo y el desarrollo de productos hipotecarios adaptados. Sin embargo, esta política sigue por el momento en proceso de prueba.

La política de facilitación del acceso al crédito concierne mayoritariamente a la metrópoli de Lima con el 33,6\% de créditos aprobados desde sus inicios en 1999.

La otra constante es que esta promoción no ha significado jamás la idea de una cultura de «todos propietarios», como ha sucedido en España o, en menor medida, en el Reino Unido. Numerosas barreras de seguridad han sido mantenidas para limitar los casos de hogares que no podrían pagar su crédito ni financiar el mantenimiento de su vivienda. Hoy en día, algunos temen que se renuncie a esta medida y que el acceso a la propiedad se convierta en una solución fácil para privatizar definitivamente el tema de la vivienda, convirtiéndola exclusivamente en un asunto privado, familiar, fuera del campo de la acción política y de los mecanismos de solidaridad nacional.

En todos los casos, estos debates se alejan de las problemáticas latinoamericanas para las cuales la propiedad de la vivienda sigue siendo un estatus mayoritariamente dominante, incluyendo ( $y$ a menudo sobre todo) a los más pobres. En tales contextos, queda muy poco espacio para una vivienda social de alquiler mientras que la propiedad de la vivienda, aún precaria, ofrece un mínimo de seguridad cuando los sistemas nacionales de protección social no aportan ni las garantías básicas para la supervivencia personal y familiar, ni la estabilidad de los recursos que permiten pagar un alquiler.

Sin embargo, otros temas de discusión en Francia pueden hacer eco más fácilmente de las problemáticas latinoamericanas antiguas o emergentes. Este es el caso de la «mixidad»social, de la participación ciudadana y del desarrollo sostenible.

9 Vivienda cuyo valor es equivalente a 14 UIT como máximo. 
La «mixidad10» del poblamiento, por ejemplo, es un concepto francés central en las intervenciones urbanas $y$, a la vez, una especificidad muy francesa. ¿Cree que esta opción podría ser desarrollada en las ciudades peruanas? ¿En Latinoamérica en general?

La mixidad social es efectivamente un concepto central de las políticas urbanas en Francia. Se basa en dos ideas: en primer lugar, que la sociedad funciona de manera más armoniosa si las diferentes categorías sociales coexisten; en segundo lugar, que las concentraciones de personas pobres en ciertos barrios o en ciertas comunas constituyen en sí una desventaja tanto para las personas como para los barrios. Este concepto es implementado principalmente con dos herramientas: las políticas escolares, mediante las cuales la asignación de los alumnos en la enseñanza pública intenta mezclar las características sociales, y las políticas de vivienda. Para estas últimas, coexisten dos modalidades principales:

- O se obliga a las comunas a tener un mínimo de 25\% de viviendas de alquiler social con el fin de permitir que las familias de bajos ingresos se alojen pagando un precio asequible, aun en las ciudades donde la vivienda privada tiene un costo elevado;

- O se intenta diversificar la oferta de vivienda en los barrios populares demoliendo los inmuebles más deteriorados y construyendo nuevos productos inmobiliarios que son destinados a atraer a hogares más acomodados.

La investigación en ciencias sociales, y particularmente la sociología francesa, han desarrollado puntos de vista críticos acerca de estas políticas, críticas que pueden, a mi parecer, acercarse a ciertos cuestionamientos sobre las ciudades latinoamericanas. Las podemos sintetizar en tres rubros:

- El primero hace referencia a la falta de precisión de la definición de la diversidad social y sobre todo a lo que, frecuentemente, no está dicho. En efecto, en las leyes o en las políticas tal y como se expresan públicamente, nada precisa verdaderamente los contornos de la mixidad esperada. ¿Se trata de una mixidad entre ricos y pobres, entre jóvenes y viejos, entre familias y personas que viven solas, entre hombres y mujeres? La legislación más reciente11 solo evoca las desigualdades de ingresos, pero para muchos de los actores, la noción y su implementación local conciernen primero a cuestiones étnicas o de origen geográfico de los hogares. Ahora bien, la ley francesa prohíbe toda referencia al origen, a la pertenencia étnica o a la filiación religiosa de las personas. De hecho, la introducción de criterios de esta naturaleza en toda decisión pública o privada (atribución de una vivienda u obtención de un préstamo, por ejemplo)

10 La «mixité» en francés se refiere a la diversidad social del poblamiento. El concepto de «mixidad social» ha sido introducido en el marco de la «Ley de orientación para la ciudad» (Loi d'Orientation pour la Ville) del 13 de julio de 1991, en respuesta a la concentración de poblaciones desfavorecidas en zonas periurbanas.

11 La ley del 21 de febrero de 2014 regula la delimitación de los barrios prioritarios para la intervención pública adoptando el criterio único de ingreso de sus habitantes. La ley del 27 de enero de 2017 fija nuevos objetivos de acceso a la vivienda social fuera de los barrios prioritarios y obliga a acoger un porcentaje mínimo de hogares de bajos ingresos. 
aparece como una discriminación castigada por la ley. Por lo tanto, las prácticas locales implementadas en nombre de la diversidad social aparecen a menudo como medios indirectos de discriminación con base en criterios no dichos.

- El segundo rubro de crítica de las políticas de mixidad social se basa en la defensa de las virtudes de los barrios populares. Lugares de fuerte solidaridad, estos barrios generarían problemas únicamente para aquellos que no viven allí y que, de todas formas, tampoco lo desearían. La implementación de políticas de renovación urbana, propuestas con el objetivo de diversificar la población de estos barrios, trajo algunas buenas demostraciones. Mientras que los administradores habían anticipado la idea de que los habitantes de los inmuebles demolidos soñarían con partir e irse a vivir a sectores más mixtos, se encontraron con la voluntad de la gran mayoría de permanecer en el barrio a fin de preservar las sociabilidades populares del vecindario. Mientras construían nuevos programas de vivienda propia destinados a atraer a las clases medias, sus primeros adquisidores eran los habitantes menos pobres del barrio.

- El tercer rubro de crítica de la noción de mixidad social se refiere a las verdaderas intenciones perseguidas. Atraer a una nueva población a los barrios populares puede conducir, cuando los objetivos se logran, a un desalojo progresivo de los hogares más pobres o considerados, por múltiples razones, como indeseables. La mixidad social se convierte entonces en «gentrificación». El fenómeno afecta primero a los barrios populares del centro de las grandes ciudades y a ciertos barrios cercanos a la periferia con fuertes tradiciones obreras. A menudo espontáneo en sus inicios (es allí cuando algunos hogares «pioneros» logran alojarse confortablemente a precios más bajos que en los barrios residenciales), este proceso puede acelerarse mediante políticas de transformación y de valorización urbana argumentadas en términos de diversidad social, pero cuyos resultados (y a veces objetivos no dichos) excluyen aún a más personas de las «categorías populares».

En los tres casos, me parece que podemos encontrar situaciones similares en América Latina, aunque el término mixidad social es poco utilizado. De hecho, las cuestiones étnicas son intensas, la identidad popular muy marcada y los mecanismos de segregación urbana son mucho más fuertes que en Europa.

\section{América Latina ha sido un modelo con relación a las innovaciones en materia de participación, aunque los esfuerzos realizados sufren muchas limitaciones y críticas en la actualidad. ¿Cuál es la posición de Francia frente a este tema? ¿Cuál es el lugar dado a la participación en las políticas y en los proyectos de intervención en las viviendas sociales?}

Efectivamente América Latina ha sido pionera en materia de participación de los habitantes en la producción de la ciudad y del hábitat popular. Las experiencias que han sido llevadas a cabo (como en los casos brasileño y peruano) son muchas veces citadas como referencias acerca de cómo las clases populares pueden apoderarse de la toma de decisiones sobre su futuro urbano y organizarse colectivamente para apropiarse del desarrollo de sus barrios y viviendas. 
En Francia, las gestiones participativas han tardado en ganar el campo urbano, tal vez porque la democracia representativa se ejerce a un nivel extremadamente fino (hay cerca de 36000 comunas en Francia) y permite una gran proximidad entre los administrados y sus autoridades locales. El progreso es aún más restringido en el sector de la vivienda donde, desde el punto de vista de las políticas locales, muchas autoridades temen (a menudo con razón) que la introducción de una mayor participación de los ciudadanos en la toma de decisiones desemboque en tentaciones maltusianas. Las políticas de construcción de nuevas viviendas son frecuentemente impopulares, especialmente si se trata de viviendas sociales que atraen a nuevos vecinos de bajos ingresos, cuya proximidad se teme genere una desvalorización residencial. De hecho, es significativo que los documentos de planificación que involucran el hábitat (los Programas Locales del Hábitat-PLH) no dan lugar a una encuesta pública, a diferencia de los demás documentos de urbanismo.

En el dominio específico de la vivienda social, la participación de los habitantes está igualmente organizada a través de una forma de democracia representativa ya que los representantes de los inquilinos son elegidos cada cuatro años e integran el consejo de administración de los organismos arrendadores. Estos representantes, muy presentes en las instancias donde hacen escuchar la voz de sus electores, no tienen sin embargo más que una legitimidad limitada por la muy escasa participación de los inquilinos en las elecciones (entre 15 y 20\% de participación según los arrendadores). Estamos lejos de una verdadera participación ciudadana en la toma de decisiones. Como única excepción, desde mediados de los años 1990, cuando un arrendador social desea iniciar una operación de rehabilitación de un inmueble, debe pedir la aprobación de los habitantes del edificio, organizando una votación que puede bloquear el proyecto en caso de desaprobación.

En un registro diferente, desde hace algunos años, nuevas formas de producción de la vivienda empiezan a aparecer en Francia, inspiradas en modelos muy presentes en otros países europeos (Alemania, Suiza) o americanos (especialmente en Canadá): el hábitat participativo. Se trata de proyectos de producción de inmuebles o de lotización de casas individuales propuestos bajo la iniciativa de grupos constituidos por los futuros habitantes de dichos conjuntos inmobiliarios. Al evitar pasar por los promotores privados y al concebir ellos mismos su hábitat, estos grupos buscan reducir ciertos costos de producción, pero también producir un hábitat adaptado a sus aspiraciones, conteniendo frecuentemente locales de uso colectivo y compartido.

Aunque hoy en día se trata de un número muy limitado de operaciones, estas experiencias se difunden rápidamente, cada vez más a menudo con el apoyo de las colectividades locales que aportan terrenos a muy bajo precio para promover estos proyectos. El futuro dirá si estas nuevas formas de producción serán significativas y si los proyectos de vida colectiva que vienen con ellas resultarán realmente sostenibles. Las primeras observaciones muestran que se está muy lejos del hábitat popular y que muchos de estos grupos están compuestos, en su mayoría, por hogares de clase media alta en busca de nuevos modos de vida 
urbana. Algunos contribuyen a su vez, por la localización de sus proyectos, a mecanismos de gentrificación de las comunas populares de las periferias de las grandes ciudades francesas.

Existen avances importantes en Francia en materia de ciudad sostenible. Destaca en particular la experiencia de los ecobarrios, que están siendo desarrollados en barrios ya existentes, los mismos que se rehabilitan con criterios de sostenibilidad tanto ambiental como social. ¿Qué nos podría decir al respecto? ¿Qué tipos de barrios abarcan estas experiencias y cómo se maneja el componente social?

La mayor parte del progreso en Francia, en cuanto a la ciudad sostenible se refiere al problema de la movilidad, en un país que continúa muy marcado por la expansión urbana y el hábitat en casas individuales periurbanas. Se trata entonces de encontrar los medios para reducir a la vez el número de desplazamientos, su costo por hogar (los gastos de transporte ocupan el segundo lugar en el presupuesto de los hogares en Francia, luego del alojamiento) y las emisiones de gases de efecto invernadero. Estas políticas afectan también al centro de las grandes ciudades donde el objetivo es reducir al máximo el uso de vehículos individuales. Al igual que en muchas metrópolis europeas, es un eje sólido de la política de la ciudad de París, que depende del mejoramiento de los sistemas de transporte público.

En el sector del hábitat y, en general, de la producción urbana, tuvo mucha resonancia en el curso de los años 2000 y 2010 la construcción de ecobarrios, a veces presentados como ilustraciones de lo que podría ser la ciudad del mañana, compacta y frugal. Sin embargo, el entusiasmo es un poco menor hoy por numerosas razones, de las cuales citaré tres:

La primera razón es evidentemente el carácter persistentemente marginal del impacto de estos ecobarrios. La construcción anual de nuevas viviendas representa en Francia apenas el 1\% del stock existente y menos de un cuarto de esta producción se realiza en el marco de operaciones de urbanismo (el resto es una construcción diseminada en ciudades o en zonas periurbanas) que no son en su totalidad ecobarrios. Pasarán muchos años antes de que esta producción pueda tener un impacto medioambiental perceptible. La segunda razón es que, hasta hoy, el costo bastante elevado de estos barrios ecológicos tiende a reservarlos a operaciones con compradores de altos ingresos. Estamos lejos de la ciudad popular y es significativo que las operaciones de renovación urbana llevadas a cabo en los barrios populares muy rara vez hayan sido consideradas como ecobarrios. La tercera razón de las dudas suscitadas por estas operaciones son las dificultades de apropiación, por parte de los hogares, de los instrumentos técnicos que deben garantizar el carácter ecológico y durable del hábitat producido. Vivir en una vivienda de consumo energético muy bajo, o incluso de energía positiva, supone cambiar ciertos hábitos de vida y aprender a utilizar la tecnología que la acompaña. Hasta ahora, estas dificultades siguen siendo importantes y, en los 
escasos barrios terminados y habitados, los resultados tardan en ser positivos. Tal vez sea una cuestión de tiempo.

En todo caso, la lentitud del desarrollo de los ecobarrios demuestra la necesidad de realizar mayores intentos para mejorar las viviendas existentes, ya que el $40 \%$ de la emisiones de gases de efecto invernadero en Francia provienen de este sector. El esfuerzo a emprender es considerable. Se inicia en el sector de la vivienda social, donde los organismos arrendadores han tomado conciencia del problema. Defienden sus operaciones de mejora del patrimonio argumentando que permiten reducir los gastos de calefacción para sus inquilinos. Ello compensa el aumento de los costos de alquiler generado por las renovaciones, subvencionadas solo en parte por el Estado. Esto es más difícil con las viviendas privadas, a veces más antiguas y consumidoras de mucha energía, particularmente en el caso de las casas individuales. En este caso también se implementaron las ayudas financieras del Estado, pero estas no cubren la totalidad de los trabajos. Esto provoca un aumento de las desigualdades entre los propietarios que pueden asumir financieramente esta mejora y aquellos que no pueden hacerlo. Al cabo de cierto tiempo, podría generar también desigualdades en la valorización del patrimonio de los propietarios, entre las viviendas con buenas prestaciones cuyo valor se haya preservado e incluso incrementado, y las otras, expuestas a mayores depreciaciones. Por lo tanto, la problemática de la sostenibilidad podría convertirse en un factor de desigualdades sociales mayores ligadas al patrimonio de los hogares.

\section{Las problemáticas del hábitat popular no se presentan de la misma manera en las metrópolis y en ciudades de menor tamaño. En Francia, ise toma en cuenta esta diferencia en las políticas urbanas? ¿Cómo se atiende esta diferencia? ¿Qué tipo de reflexión nos podría generar esto para el caso peruano?}

Una de las mayores evoluciones de la problemática urbana en Francia desde el inicio de los años 2000 es el fuerte crecimiento de las desigualdades territoriales entre la metrópoli parisina, en el centro de una región de 12 millones de habitantes (sobre un total nacional de 67 millones), las otras metrópolis del país, las ciudades pequeñas y medianas y los espacios rurales.

El área metropolitana de París concentra la mayoría de los síntomas de aquello que se denomina «la crisis de la vivienda» en Francia: déficit cuantitativo de la oferta, precio muy elevado tanto en el alquiler como en la compra-venta, poca actividad de construcción y concentración, en ciertos municipios, de una población pobre y frecuentemente inmigrante. Estas dificultades se relacionan en parte con la incapacidad de implementar una estructura eficaz de manejo de las áreas metropolitanas. Aún hoy en día es la escala comunal la que domina, favoreciendo muchas veces egoísmos microlocales: existen 1280 comunas en la región de île-de-France donde se encuentra la capital; la ciudad de París es una de esas comunas y cuenta con solo dos millones de habitantes, es decir, uno de cada seis habitante de la región). Las reformas están en marcha con la creación, en el año 2016, de la Metrópolis del Gran París (Métropole du Grand Paris), que cubre 
la mayor parte de la zona urbana de la región. Sin duda tomará varios años antes de que estas reformas comiencen.

\section{Cuadro 3 - Especificidad de la vivienda social a escala subnacional, a partir del ejemplo de algunas grandes ciudades}

Cantidad de viviendas sociales en algunas grandes ciudades en Francia y porcentaje del total de las viviendas, en 2013

\begin{tabular}{|l|r|c|}
\hline \multirow{2}{*}{ Unidad urbana } & \multicolumn{2}{|c|}{2013} \\
\cline { 2 - 3 } & \multicolumn{1}{|c|}{ Número } & $\%$ \\
\hline París & 1063030 & 23,5 \\
Lyon & 133933 & 19,0 \\
Marseille & 114323 & 16,6 \\
Nice & 40467 & 9,2 \\
Total Francia & 4171735 & 14,6 \\
\hline
\end{tabular}

Fuente: INSEE (2013)

Repartición de la ayuda a la vivienda social en el Perú en ciertas regiones en $2013^{12}$

\begin{tabular}{|c|c|c|c|c|}
\hline \multirow[b]{2}{*}{ Región } & \multirow{2}{*}{$\begin{array}{c}\text { Hogares } \\
\text { beneficiarios } \\
\text { de MiVivienda } \\
\text { o Techo Propio } \\
\text { en } 2013\end{array}$} & \multirow{2}{*}{$\begin{array}{c}\text { \% de viviendas } \\
\text { sociales con relación } \\
\text { al conjunto de } \\
\text { residencias a nivel } \\
\text { nacional } \\
\text { (datos agregados de } \\
1999-2013 \text { ) }\end{array}$} & \multicolumn{2}{|c|}{$\begin{array}{l}\text { Repartición del apoyo a la vivienda social } \\
\text { (en \% de hogares, datos agregados de } \\
\text { 2004-2013) }\end{array}$} \\
\hline & & & $\begin{aligned} & \text { Mivienda } \\
&+ \text { Techo Propio } \\
& \text { (con relación al } \\
& \text { total nacional) }\end{aligned}$ & $\begin{array}{l}\text { Solo subvenciones } \\
\text { Techo Propio (con } \\
\text { relación al total de } \\
\text { vivienda social) }\end{array}$ \\
\hline Lima & 76622 & $3,2 \%$ & $33,6 \%$ & $61,9 \%$ \\
\hline Callao & 8793 & $3,7 \%$ & $4,3 \%$ & $4,3 \%$ \\
\hline Arequipa & 7347 & $1,7 \%$ & $3,4 \%$ & $5,2 \%$ \\
\hline Cusco & 1560 & $0,5 \%$ & $0,6 \%$ & $1,0 \%$ \\
\hline Piura & 12140 & $2,7 \%$ & $6,0 \%$ & $3,6 \%$ \\
\hline $\begin{array}{l}\text { La Libertad } \\
\text { (Trujillo) }\end{array}$ & 25505 & $5,8 \%$ & $12,5 \%$ & $6,3 \%$ \\
\hline Total Perú & 211742 & $2,6 \%$ & $100,0 \%$ & $40,3 \%$ \\
\hline
\end{tabular}

Fuente: Página web del Fondo MiVivienda S.A.

12 En Francia, París presenta una cantidad de viviendas sociales más elevada que otras ciudades del país. En el Perú, Lima concentra también la mayor parte de la ayuda, en particular en lo que concierne a los créditos MIVIVIENDA y, en menor medida, en lo que concierne al apoyo vía Techo Propio. Cabe notar que la proporción de crédito MIVIVIENDA con base en el total del apoyo a la vivienda social tiende a disminuir en Lima: más del $60 \%$ de los hogares que fueron beneficiarios de algún tipo de ayuda entre 2004 y 2013 recibieron subvenciones Techo Propio. 
En cambio, las metrópolis de provincia (ciudades como Lyon, Toulouse, Bordeaux, Nantes...) están estrechamente comprometidas desde hace casi veinte años en políticas de aglomeración ofensivas y eficaces. Gracias a la descentralización gozan de una gran autonomía de decisión. Sus alcaldes frecuentemente son personalidades políticas de nivel nacional y su ciudad es para ellos una suerte de «bandera política». Asimismo, las metrópolis de provincia son para ellos una oportunidad para demostrar su eficiencia en la transformación del espacio urbano a través de grandes proyectos que involucran la construcción de muchas viviendas sociales y privadas. Si bien existen importantes desigualdades entre estas ciudades (Marseille, por ejemplo, es mucho menos avanzada que las otras), en términos generales, ellas son las principales beneficiarias de la descentralización progresiva de las políticas urbanas.

La situación de las ciudades pequeñas y medianas sigue siendo diferente. Más del $20 \%$ de la población del país vive allí, pero el atractivo económico y residencial de muchas de ellas tiende a descender, excepto en los sectores turísticos. Hoy en día, estas ciudades son bastante vulnerables frente a la baja de sus recursos, a la pérdida de su población y a la desertificación residencial y comercial de sus centros. A diferencia de las metrópolis, pueden aparecer como víctimas de la descentralización y del proceso de metropolización. Ellas sufren a la vez el retiro industrial y de los medios tradicionales de redistribución vinculados a la presencia del Estado en el territorio (puestos de funcionarios, servicios públicos...), mientras que a menudo cuentan con insuficientes medios financieros, ingeniería local e influencia política.

La situación de estas ciudades pequeñas y medianas comienza a aparecer como uno de los problemas urbanos de hoy y de mañana. Queda mucho por hacer para incluirlas realmente en las políticas del Estado, en un contexto general de disminución del gasto público. Me parece que su ejemplo puede servir también para la reflexión de todos los países que, como el Perú, atraviesan procesos de descentralización. Esta situación destaca el importante potencial de desarrollo y de iniciativa local, puesto en valor por un cierto alejamiento en cuanto a la tutela del Estado central y el riesgo que representa para quienes no cuentan con los medios financieros, humanos y políticos suficientes para asumir esas responsabilidades.

\section{Finalmente, «iCiudades populares, ciudades sostenibles?», zidentifica algunas líneas para pensar estas ciudades a menudo artificialmente opuestas?}

En realidad, no creo que sean verdaderamente opuestas y podríamos agregar entre las dos, «ciudad mixta». La capacidad de recibir a las clases populares en todas partes de la ciudad, y de permitir que cada individuo elija el entorno donde quiere vivir, me parece un desafío mayor para las políticas urbanas. Desafío que el mercado no permite alcanzar, más bien al contrario. Ahora bien, ¿cómo calificar de sostenible a una ciudad construida con base en mecanismos de segregación? Hacer posible para todos y en todo lugar, a partir de la vivienda, el acceso a los servicios públicos de transporte, de educación, de cultura, como también a los 
lugares de trabajo, es una manera de mejorar la sostenibilidad de las ciudades, reduciendo a la vez las distancias sociales y las distancias de desplazamiento. Formulado de esta manera, el objetivo puede parecer utópico, incluso ingenuo si la mirada permanece fijada en los objetivos a corto plazo de un mandato electoral. Pero si se concibe como una meta a largo plazo, objeto de un esfuerzo constante, me parece poder constituir lo esencial de las políticas urbanas y conjugar al mismo tiempo lo social y lo sostenible.

\section{Referencias citadas}

COMMISSARIAT GÉNÉRAL AU DÉVELOPPEMENT DURABLE, 2015 - Le parc locatif social au 1er janvier 2015. Chiffres \& statistiques, 696: 1-7. Disponible en http://www. statistiques.developpement-durable.gouv.fr/publications/p/2348/831/parc-locatifsocial-1er-janvier-2015.html.

DRIANT, J.-C., 1991 - Las Barriadas de Lima. Historia e interpretación, 231 pp.; Lima: Instituto Francés de Estudios Andinos (IFEA), Centro de Estudios y Promoción del Desarrollo (DESCO).

INSTITUT NATIONAL DE LA STATISTIQUE ET DES ÉTUDES ÉCONOMIQUES (INSEE), 2013 - Recensement de la population 2013.

INSTITUTO NACIONAL DE ESTADÍSTICA E INFORMÁTICA (INEI), 2015 - Encuesta Nacional de Programas Estratégicos, 2011-2014, 162 pp.; Lima: INEl. Disponible en https://www.inei.gob.pe/media/MenuRecursivo/publicaciones_digitales/Est/Lib1291/ libro.pdf.

RIOFRÍO, G. \& DRIANT, J.-C., 1987 - ¿Qué vivienda han construido? Nuevos problemas en viejas barriadas, 162 pp.; Lima: Centro de Investigación, Documentación y Asesoría Poblacional (CIDAP), Instituto Francés de Estudios Andinos (IFEA), Tarea-Asociación de Publicaciones. 